\title{
Propagação in vitro de Baptistonia pubes (Lindl.) Chiron \& V.P. Castro (Oncidium pubes Lindl.) (Orchidaceae) ${ }^{1}$
}

\author{
Alessandro Wagner Coelho Ferreira ${ }^{2,6}$, Maria Inês Salgueiro Lima ${ }^{3}$, Ricardo Tadeu de Faria ${ }^{4}$, \\ Jose Pedro Nepomuceno Ribeiro ${ }^{5}$ e Carlos Aparecido Casali ${ }^{3}$
}

Recebido em 23/04/2009. Aceito em 26/11/2009

RESUMO - (Propagação in vitro de Baptistonia pubes (Lindl.) Chiron \& V.P. Castro (Oncidium pubes Lindl. - Orchidaceae)). Baptistonia pubes é uma epífita que ocorre na Floresta Atlântica do Brasil, no Paraguai e norte da Argentina. É considerada espécie vulnerável e ameaçada de extinção. Nossos objetivos foram avaliar a eficácia da germinação de suas sementes e o crescimento em dois pHs utilizando-se dois meios de cultura: Murashige-Skoog (modificado - (MS)) e meio nutritivo à base de banana nanica acrescido de NPK 20-20-20 (Plant Prood ${ }^{\circledR}$ ) (BAN) variando-se as concentrações de nutrientes e pH para a germinação e para o crescimento inicial das plântulas. As sementes germinaram em média 15 dias após a inoculação, em todas as condições. A porcentagem de germinação variou entre 2,6 a $11,6 \%$, sendo que a maior porcentagem ocorreu no $\mathrm{pH}=5,2 \mathrm{BAN}$ e a menor no $\mathrm{pH}=6,2 \mathrm{MS} / 2$. O meio BAN foi mais eficiente na germinação. Os pHs, em cada meio, alteraram significativamente as médias das sementes germinadas. As plântulas cresceram mais no meio nutritivo à base de banana nanica no $\mathrm{pH}=5,2$.

Palavras-chave: Germinação, crescimento, variação de $\mathrm{pH}$, meios de cultura

ABSTRACT - (Propagation in vitro of Baptistonia pubes (Lindl.) Chiron \& V.P. Castro (Oncidium pubes Lindl. - Orchidaceae)). Baptistonia pubes is an epiphyte that grows in Brazilian Atlantic Forest, in Paraguay and northern Argentina. It is considered vulnerable and threatened with extinction. Our aim was to verify seed germination efficiency and growth at two pHs, using two culture mediums: Murashige-Skoog (modified - (MS)) and banana pulp with added NPK 20-20-20 (Plant Prood ${ }^{\circledR}$ ) (BAN), with varied nutrient and $\mathrm{pH}$ concentrations for germination and for growth. The seeds germinated on average 15 days after the inoculation, at all conditions. The percentage of germination varied between 2.6 and $11.6 \%$. The highest percentage was at $\mathrm{pH}=5.2 \mathrm{BAN}$ and the lowest at $\mathrm{pH}=6.2 \mathrm{MS} / 2$. The banana pulp was most efficient for germination. The $\mathrm{pHs}$, in each environment, altered significantly the averages of the germinated seeds. Seedling growth showed better results in the banana medium, $\mathrm{pH}=5.2$

Key words: Germination, growth, $\mathrm{pH}$ variation, culture medium

\section{Introdução}

As sementes de orquídeas, por serem diminutas, são desprovidas de cotilédone e têm endospermas extremamente reduzidos, insuficientes para fornecer os nutrientes necessários ao embrião durante o processo de germinação. Knudson (1922) desenvolveu um meio de cultura para a germinação assimbiótica, ou seja, que não depende dos fungos micorrízicos. Um dos meios de cultura mais utilizados para propagação in vitro de Orchidaceae é a fórmula de Murashige \& Skoog (1962). Outro tipo de meio de cultura é o que utiliza em sua formulação polpa de frutas e água de coco, mas devido ao percentual dos nutrientes dessas frutas poderem variar, dependendo do local de cultivo e do estágio de maturação, podendo este procedimento receber críticas (Arditti \& Ernst 1993). Segundo Arditti \& Ernst (1984) a maior parte das espécies de orquídeas germinam bem em pHs entre 4,8 e 5,2, com amplitude entre os pHs 3,6 e 7,6. Porém, há uma tendência das orquídeas terrestres germinarem em faixa de $\mathrm{pHs}$ mais baixos que as epífitas (Arditti et al. 1982; Diez 2007).

Embora a propagação in vitro das orquídeas esteja sendo feita há muitas décadas, existem grandes diferenças nas exigências de cada espécie (Arditti 1967; Arditti \& Ernst 1984; Stancato \& Faria 1996; Zettler \& Hofer 1997; Takahashi et al. 2000; Faria et al. 2004; Sorace et al. 2008) e assim, ainda é necessário estabelecer os melhores meios e condições de cultura para a maior parte delas. Essa carência é especialmente latente quando se trata de espécies sem interesse econômico (Arditti \& Ernest 1993). Diversas orquidáceas estão ameaçadas de extinção por viverem em ambientes fragmentados e frágeis (Tremblay et al. 2005). A elaboração de protocolos para germinação in vitro para estas espécies pode ser vital para a manutenção de suas populações na natureza (Martini et al. 2001).

Baptistonia pubes (Lindl.) Chiron \& V.P. Castro (Oncidium pubes Lindl.) é uma orquídea epífita que se desenvolvia, originalmente, em ambientes de Floresta Atlântica do Brasil, nos estados do Rio de Janeiro, Minas Gerais e São Paulo, mas também, no Paraguai e no norte da Argentina (Pabst \& Dungs 1977). Apresenta pseudobulbos fusiformes alongados (5,0-7,0 cm de comprimento e 1,0-1,5 cm de largura) e agregados devido ao rizoma curto. As folhas são subcoriáceas (duas a cinco por pseudobulbo), levemente arqueadas (7,0-12,0 cm de comprimento e 2,0-3,0 cm de largura) e a inflorescência paniculada apresenta até 300 flores amarelo-pardacentas, com $1,1 \mathrm{~cm}$ de comprimento e $0,5 \mathrm{~cm}$ de largura (Cogniaux 1904-1906). Na lista oficial de espécies de plantas ameaçadas de extinção no estado de São Paulo, é considerada espécie vulnerável (SMA 2004).

Os objetivos deste trabalho foram verificar a eficácia de dois tipos de meios de cultura com diferentes potenciais

\footnotetext{
Parte da tese de Doutorado do primeiro Autor

2 Universidade Federal do Maranhão, Pinheiros, MA, Brasil

3 Universidade Federal de São Carlos, Departamento de Botânica, São Carlos, SP, Brasil

4 Universidade Estadual de Londrina, Departamento de Agronomia, Londrina, PR, Brasil

5 Universidade Federal de São Carlos, Curso de Pós-graduação em Ecologia e Recursos Naturais, São Carlos, SP, Brasil

6 Autor para correspondência: alessandrowcf@yahoo.com.br
} 
hidrogeniônicos (pHs) sobre a germinação de sementes e o crescimento plântulas de $B$. pubes visando otimizar a produção de mudas dessa espécie.

\section{Material e métodos}

Obtenção de frutos e sementes - Os três frutos de Baptistonia pubes (Lind1.) Chiron \& V.P. Castro, foram obtidos de um indivíduo encontrado em Analândia $\left(22^{\circ} 11^{\prime} \mathrm{S} ; 47^{0} 38^{\prime} \mathrm{W}\right)$. Apenas esse indivíduo foi coletado, pois a população local estava extremamente reduzida. No momento da coleta, os frutos ainda não estavam maduros, sendo esse indivíduo de $B$. pubes mantido sob cultivo em casa de vegetação até a maturação desses frutos. As sementes foram retiradas dos três frutos com os primeiros sinais de deiscência, depositadas sobre papel toalha, separadas com auxílio de pincel e depois mantidas em frasco com sílica gel sob refrigeração a cerca de $5^{\circ}$ C (Alvarez-Pardo \& Ferreira 2006) por cinco dias. Uma amostra dessas sementes foi observada em estereomicroscópio a fim de verificar se havia embriões viáveis. Segundo Ramos (1977), as sementes que apresentam uma região nuclear contêm embriões e as transparentes, não.

Preparação dos meios de cultura - Foram utilizados dois meios de cultura: Murashige \& Skoog (1962 - modificado) e meio nutritivo à base de banana nanica acrescido de NPK 20-20-20 Plant Prood ${ }^{\circledR}$ (BAN). O meio de cultura Murashige-Skoog (1962 - modificado) foi preparado com metade da concentração dos macronutrientes (MS/2) e acrescido de $1,5 \mathrm{gL}^{-1}$ de carvão ativado; $0,5 \mathrm{mgL}^{-1}$ de Piridoxina (B6) e Tiamina (B1); $1,0 \mathrm{mgL}^{-1}$ de Ácido Nicotínico (Niacina) e $20 \mathrm{~g}$ de sacarose por litro. A adição de vitaminas do complexo B auxilia na germinação, no crescimento e desenvolvimento de Orchidaceae (Arditti et al. 1982), motivo pelo qual tal procedimento foi adotado nesse trabalho.

No meio de cultura à base de polpa de banana nanica (Musa paradisiaca L. cv. nanica) (BAN), utilizaram-se os seguintes constituintes (por litro): 50 $\mathrm{g}$ de banana nanica esverdeada (sem casca); $1,2 \mathrm{~g}$ de adubo comercial Plant Prood $^{\circledR}$ (NPK 20-20-20); $20 \mathrm{~g}$ de sacarose; 1,5 g de carvão ativado, 0,5 mg de Piridoxina (B6), 0,5 mg de Tiamina (B1), 1,0 mg de Ácido Nicotínico (Niacina); 7,5 g de ágar; água destilada para completar 1L. Para melhor exatidão do $\mathrm{pH}$ foram feitas leituras antes e depois de serem introduzidos o ágar e o carvão ativado. Em ambos meios, verificamos que antes da adição desses produtos o pH se torna $0,4-0,6$ mais baixo. Este parâmetro foi ajustado para 5,2 ou 6,2 , dependendo do tratamento, à temperatura ambiente (cerca de $\left.28{ }^{\circ} \mathrm{C}\right)$, utilizando-se $\mathrm{HCl}(0,2 \mathrm{~N})$ ou $\mathrm{KOH}(0,2 \mathrm{~N})$. Em todos os frascos de semeadura foram utilizados $40 \mathrm{~mL}$ de meio de cultura. Os meios foram autoclavados a $120^{\circ} \mathrm{C}$, por 20 minutos. Após a inoculação das sementes em fluxo laminar, os frascos foram envolvidos em filme de PVC.

Contagem das sementes - Para a avaliação do número de sementes a serem utilizadas nos bioensaios de germinação foram pesadas cinco amostras de 0,0001 g. Cada uma delas foi transferida para um tubo plástico cônico graduado de $15 \mathrm{~mL}$, com tampa de rosca, onde foram acrescentados $10 \mathrm{~mL}$ de solução desinfestante ( 3 gotas de Tween 20, $160 \mathrm{~mL}$ de água destilada e $40 \mathrm{~mL}$ de hipoclorito de sódio $0,4 \%$ - modificado de Alvarez-Prado et al. 2006). Em seguida os tubos foram agitados por cinco minutos deixandose por mais cinco em repouso. Aos $10 \mathrm{~mL}$ foi adicionada água destilada suficiente para a retirada da solução desinfestante e eventuais sementes inviáveis. A seguir, os tubos foram agitados por mais cinco minutos e por igual tempo deixados em repouso. Com auxílio de pipeta de Pasteur, o excesso da água foi retirado, evitando a suspensão das sementes, até que restassem 3,5 mL. Destes foram retiradas e contadas dez alíquotas de $30 \mu \mathrm{L}$ de cada tubo. A seguir foram calculadas as médias do número de sementes nas amostras de $30 \mu \mathrm{L}$.

Inoculação das sementes - Foi realizada de acordo com o procedimento citado na contagem das sementes. Quando necessário, uma película de água destilada autoclavada foi adicionada antes, para que as sementes ficassem distribuídas uniformemente na superfície do meio de cultura.

Inoculação das sementes nos meios de cultura para análise do percentual de germinação nos diferentes $\mathrm{pHs}$ - Para verificação da influência do $\mathrm{pH}$ na germinação das sementes de $B$. pubes, foram pesadas quatro novas alíquotas de 0,0001 $\mathrm{g}$ de sementes, as quais foram transferidas para quatro tubetes de $15 \mathrm{~mL}$. A lavagem das sementes foi realizada como citado anteriormente, porém a desinfestação foi realizada no interior da câmara de fluxo laminar com quinze minutos de agitação dos tubos. Cada um dos quatro tubetes serviu para inocular dez frascos. Foram utilizados ambos os meios citados, com os pHs ajustados para 5,2 e 6,2. No meio MS/2, foram semeados dez frascos com $\mathrm{pH}=5,2 \mathrm{e}$ dez frascos com $\mathrm{pH}=6,2$. No meio BAN adicionado de NPK 20-20-20, foram semeados dez frascos com $\mathrm{pH}=5,2$ e dez frascos $\operatorname{com} \mathrm{pH}=6,2$. A inoculação das sementes foi feita em fluxo laminar. O meio aquoso desinfestado contendo as sementes foi homogeneizado sugando-se e bombeando-se $30 \mu \mathrm{L}$ por dez vezes. Após três segundos, colheu-se uma alíquota de $30 \mu \mathrm{L}$ dessa solução contendo sementes, que foi transferida dez vezes em cada um dos quatro meios de cultura, totalizando os 40 frascos. Após a inoculação os frascos foram envolvidos em filme de PVC e levados para sala de crescimento com temperatura $25 \pm 2^{\circ} \mathrm{C}$, fotoperíodo de 16 horas e intensidade luminosa de 1600 lux. Passados três meses de cultura, as plântulas obtidas foram contadas a fim de verificar o percentual de germinação. Os dados obtidos foram testados quanto à sua normalidade e homogeneidade e posteriormente analisados pelo teste ANOVA com pósteste de Tukey a $5 \%$ (Zar 1999).

Crescimento e desenvolvimento das plântulas -20 frascos com meio de cultura $(\mathrm{MS} / 2 ; \mathrm{pH}=5,2)$ e 20 frascos com meio de cultura $\mathrm{BAN}$; $\mathrm{pH}=5,2$ foram semeados em fluxo laminar conforme o método utilizado anteriormente. Na fase de crescimento, o meio MS foi utilizado integralmente quanto aos componentes minerais, uma vez que as plântulas exigem mais nutrientes do que as sementes, conforme sugerido por Unemoto et al. (2007). A quantidade de meio de cultura em cada frasco de repique foi de $80 \mathrm{ml}$.

Depois de quatro meses de cultura em sala de crescimento (temperatura de $25 \pm 2^{\circ} \mathrm{C}$, fotoperíodo de 16 horas e intensidade luminosa de 1600 lux.), as plântulas com $1,0 \pm 0,5 \mathrm{~cm}$ foram transferidas, em fluxo laminar, para os respectivos meios de cultura MS (modificado) e BAN sendo: MS (modificado) - 16 frascos, oito em $\mathrm{pH}=5,2$ e oito em $\mathrm{pH}=6,2$; $\mathrm{BAN}-16$ frascos, oito em $\mathrm{pH}=5,2$ e oito em $\mathrm{pH}=6,2$. Após a transferência, os 32 frascos com 10 plântulas em cada um e mantidos no mesmo ambiente, por cerca de oito meses. Após esse período in vitro, as plântulas tiveram os seguintes parâmetros medidos: massa fresca total, comprimento da maior parte aérea, comprimento da maior raiz e número de raízes. Os dados obtidos foram testados quanto à sua normalidade e homogeneidade e posteriormente analisados pelo teste ANOVA com pós-teste de Tukey a 5\% (Zar 1999).

\section{Resultados e discussão}

As médias das 10 contagens em lupa das alíquotas de sementes de $B$. pubes, em cada um dos cinco tubos, foram semelhantes. Por esse motivo, adotou-se o mesmo procedimento na inoculação das alíquotas dessas sementes nos meios de cultura utilizados para verificar o percentual de germinação.

As sementes germinaram em média 15 dias após a inoculação nos meios de cultura, em todas as condições. A porcentagem de germinação variou entre 2,6 a 11,6\%, sendo que a maior porcentagem ocorreu no $\mathrm{BAN} \mathrm{pH}=5,2 \mathrm{e}$ a menor no $\mathrm{MS} / 2 \mathrm{pH}=6,2$. Portanto, o meio de cultura BAN foi mais eficiente na germinação do que o meio MS/2. Embora o $\mathrm{pH}$ 5,2 tenha sido o mais favorável para germinação em ambos meios de cultura, o meio $\mathrm{BAN} \mathrm{pH}=6,2$, foi tão favorável quanto o meio $\mathrm{MS} / 2 \mathrm{pH}=5,2$. Os $\mathrm{pHs}$, em cada meio, alteraram significativamente as médias das sementes germinadas mostrando que uma diferença de $\mathrm{pH}$ de 5,2 para 6,2 já é suficiente para alterar este parâmetro (Tab. 1).

No ensaio de crescimento, quando se comparam os meios, as plântulas no meio nutritivo à base de banana nanica se mostraram estatisticamente iguais ou maiores para todos os parâmetros analisados (Tab.1). 
Tabela 1. Dados seguidos pela mesma letra não são significativamente diferentes pelo Teste de Tukey $5 \%$. * Na germinação foi utilizado MS/2 e no crescimento MS integral. NMP = Número Médio de Plântulas; \%G = Porcentagem de Germinação; PMP = Peso Médio das Plântulas; CMMF = Comprimento Médio da Maior Plântula; CMMR = Comprimento Médio da Maior Raiz; NMR = Número Médio de Raízes.

\begin{tabular}{|c|c|c|c|c|c|c|}
\hline Tratamento & NMP & $\% \mathrm{G}$ & PMP (gramas) & CMMF (cm) & CMMR $(\mathrm{cm})$ & NMR \\
\hline$*$ MS-pH 5,2 & $5,8 \pm 1,8 \mathrm{~B}$ & 5,9 & $0,440 \mathrm{~A}$ & $4,563 \mathrm{~A}$ & $2,062 \mathrm{~A}$ & $3 \mathrm{~A}$ \\
\hline *MS-pH 6,2 & $2,6 \pm 0,9 \mathrm{C}$ & 2,6 & $0,419 \mathrm{AB}$ & $5,143 \mathrm{~A}$ & $2,0212 \mathrm{~A}$ & $3,112 \mathrm{~A}$ \\
\hline BAN-pH 5,2 & $11,4 \pm 2,6 \mathrm{~A}$ & 11,6 & $0,733 \mathrm{C}$ & $7,323 \mathrm{~B}$ & $6,042 \mathrm{~B}$ & $5,187 \mathrm{~B}$ \\
\hline BAN-pH 6,2 & $6,1 \pm 1,1$ B & 6,2 & $0,316 \mathrm{~B}$ & $7,230 \mathrm{~B}$ & $4,376 \mathrm{C}$ & $3,225 \mathrm{~A}$ \\
\hline
\end{tabular}

Ao comparar os pHs, dentro do mesmo meio, nota-se que sobre o MS/2 não existem diferenças significativas entre os $\mathrm{pHs}$ 5,2 e 6,2 em relação ao peso fresco das plântulas, comprimento médio da maior raiz, da maior folha e do número médio de raízes. Para o meio nutritivo à base de banana nanica, no entanto, houve diferenças significativas entre os pHs 5,2 e 6,2, para peso fresco das plântulas, comprimento médio da maior raiz e número médio de raízes. Não houve diferenças significativas para o comprimento médio da maior folha (Tab. 1).

Quanto à micropipetagem das sementes em água destilada, a pequena quantidade de propágulos de $B$. pubes por frasco, 98 em média, facilitou a leitura da germinação no meio de cultura. As sementes não ficaram aderidas à ponteira da micropipeta e a película de água na superfície do meio de cultura proporcionou uma distribuição mais uniforme das sementes. Como o tamanho das sementes de orquídeas varia de 0,25 a 1,2 mm (Arditti 1967), é necessário fazer as contagens em cada espécie para verificar qual a média esperada.

A porcentagem de germinação variou entre 2,6 a 11,6\% (Tab. 1), sendo considerada baixa para o processo assimbiótico, que pode alcançar até $100 \%$ de germinação, conforme a espécie, o meio de cultura e as condições sob as quais as culturas são mantidas (Hoshi et al. 1994). Porém, na natureza, a germinação das sementes de Orchidaceae chega até 5\% (Rao 1977). Mesmo assim, nas culturas que utilizaram o meio de cultura BAN em $\mathrm{pH}=5,2$, a germinação foi mais do que o dobro do que geralmente ocorre na natureza, confirmando que a propagação in vitro tende a ser mais eficiente (Tab. 1). O baixo percentual de germinação de $B$. pubes pode estar relacionado com os pHs utilizados, que podem não estar na faixa de $\mathrm{pH}$ ótimo para a espécie. Para dados mais conclusivos seria necessário testar uma faixa mais ampla de pHs e também intervalos menores entre eles.

Outro aspecto a ser destacado é que foram utilizadas sementes de três frutos produzidos por um único indivíduo proveniente de uma população reduzida, cerca de 60 indivíduos, a maioria formando pequenos grupos de dois a cinco indivíduos, em uma área de aproximadamente 10 ha. Segundo Charlesworth \& Charlesworth (1987) e Tremblay et al. (2005), a origem do pólen, da mesma planta, de um exemplar geneticamente próximo ou de uma população distante, pode influenciar a genética da semente e o vigor das plântulas.

$\mathrm{O}$ meio à base de banana não tem mostrado ser apenas mais eficiente no acúmulo de biomassa das plântulas de orquídeas (Stancato et al. 2008), mas também é mais simples em seu preparo. No meio MS os compostos nitrato de amônio e nitrato de potássio são controlados pelo Ministério da Defesa (Brasil 2000; Unemoto et al. 2007), o que torna sua aquisição dificultada por pessoas não pertencentes às universidades ou à Institutos de pesquisa. Os meios normalmente utilizados em culturas de orquídeas são de constituição complexa (Arditti \& Ernest 1993; Alvarez-Pardo et al. 2006b). É necessário que sejam estudadas as necessidades particulares de cada espécie, variando-se os meios de forma a atender cada uma delas. Desta forma, com o uso de formulações simples, pode-se minimizar as pressões exercidas pela coleta predatória dessas espécies.

As diferenças encontradas entre os resultados obtidos no meio nutritivo a base de banana e no meio Murashige-Skoog são grandes, chegando a quase três vezes em alguns parâmetros, por exemplo, germinação de sementes em pH 6,2 e comprimento médio da maior raiz emitida em pH 5,2 (Tab. 1). Estes resultados estão coerentes com os apresentados na literatura. Assim, Stancato et al. (2008) testaram os meios nutritivos 10:10:10(N:P:K), na concentração de $1 \mathrm{gL}^{-1} ; 10: 30: 20,1 \mathrm{gL}^{-1}$; polpa de maçã, $10 \mathrm{gL}^{-1}$; polpa de tomate, $10 \mathrm{~g} / \mathrm{L}^{-1} ; 10: 30: 20,1 \mathrm{gL}^{-}$ 1; polpa de banana, $50 \mathrm{gL}^{-1}$; e também as formulações propostas por Knudson (1946), Vacin \& Went (1949) e Murashige \& Skoog (1962) no cultivo de plântulas de Laelia longipes Rchb., L. tenebrosa Rolfe e Miltonia spectabilis Lindley. Nas plântulas de L. longipes, cultivadas em 10:10:10 e polpa de banana foi observado um maior acúmulo de massa seca e naquelas cultivadas em MS o menor, com resultados semelhantes para $M$. spectabilis embora o meio 10:30:20 tenha resultado em maior acúmulo de massa seca nas plântulas. Em ordem decrescente de acúmulo de matéria seca total estão os meios 10:30:20 e polpa de banana, seguidos por 10:10:10, polpa de tomate, Knudson, Vacin e Went, polpa de maçã e MS. Para L. tenebrosa, as plântulas cultivadas no meio polpa de banana incorporaram o maior conteúdo de matéria seca, seguidas pelas plântulas cultivadas em meio com 10:10:10.

Millner et al. (2008) utilizaram os meios MurashigeSkooge, Phytotech P 668, Vacin \& Went e Western para a germinação e desenvolvimento inicial dos protocormos de Restrepia brachypus Rchb. f. Para o meio Western encontraram a maior taxa de germinação (53\%), o segundo maior diâmetro para os protocormos $(325 \mu \mathrm{m})$ e, com banana, o maior comprimento de plântula $(3,6 \mathrm{~mm})$. Nossos resultados 
também mostraram maior eficiência do meio com banana para o crescimento médio da maior folha e para o comprimento médio da maior raiz (Tab. 1).

Aktar et al. (2008) trabalhando com cultura de tecidos de Dendrobium sp. encontraram diferenças significativas entre diferentes meios e aditivos orgânicos no desenvolvimento de protocormos e subsequente formação de plântulas. Os meios utilizados foram: Knudson C (KC), Vacin e Went, Murashige-Skoog (MS) e New Phalaenopsis. Exceto para o comprimento de brotamentos e folhas, os maiores valores de todos os parâmetros foram obtidos da interação do meio $\mathrm{MS} / 2$ com polpa de Musa paradisiaca L. cv. Sabri. Entretanto os brotamentos maiores foram encontrados no meio $\mathrm{KC}$ com polpa de banana Sabri e as folhas mais longas com $\mathrm{KC}$ e MS/2 com polpa de banana Sabri, mostrando novamente a eficácia do uso da polpa de banana.

Assim, embora essa prática reduza a replicabilidade dos resultados obtidos, a adoção de meios nutritivos contendo polpa de banana parece aumentar significativamente a eficiência na produção de mudas de orquidáceas em laboratório.

\section{Agradecimentos}

Os autores agradecem ao técnico Geraldo Lopes da Silva do Departamento de Fitotecnia da Universidade Estadual de Londrina pelo auxílio no trabalho experimental; ao Dr. Armando Henriques Vieira e ao técnico Luiz Sartori do Departamento de Botânica da Universidade Federal de São Carlos, pelo auxílio no trabalho em laboratório. À CAPES pela bolsa de doutoramento concedida ao primeiro autor.

\section{Referências bibliográficas}

Alvarez-Pardo, V.M. \& Ferreira, A.G. 2006. Armazenamento de sementes de orquídeas. Revista Brasileira de Sementes 28: 92-98

Alvarez-Pardo, V.M.; Ferreira, A.G. \& Nunes, V.F. 2006. Métodos de desinfestação de sementes para cultivo in vitro de orquídeas epífitas do Sul do Brasil. Horticultura Brasileira 24: 217-220.

Aktar, S.; Nasiruddin, K.M. \& Hossain, K. 2008. Effects of Different Media and Organic Additives interation on in vitro regeneration of Dendrobium Orchid. Journal of Agriculture \& Rural Development 6: 69-74.

Arditti, J. 1967. Factors affecting the germination of orchid seeds. Botanical Review 33: 1-97.

Arditti, J.; Clements, G.; Fast, G.; Hadley, G.; Nishimura, G. \& Ernst, R. 1982. Orchid seed germination and seedling culture - A manual. Pp. 244-370. In: Arditti, J. (ed.) Orchid biology: reviews and perspectives II. New York, Cornell University Press.

Arditti, J. \& Ernst, R. 1984. Physiology of germinating orchid seeds. Pp. 177-222. In: J. Arditti (ed.) Orchid biology: reviews and perspectives III. New York, Cornell University Press.

Arditti, J. \& Ernest, R. 1993. Micropropagation of Orchids. New York, John Wiley \& Sons (eds.).

Brasil 2000. Ministério da Defesa. Decreto-Lei n. 3665, de 20 de novembro de 2000. Estabelece os critérios para o regulamento de uso de produtos controlados (http://br.vlex.com/vid/nova-regulamento-produtoscontrolados-34332859. Acesso em 07/03/2009).
Charlesworth, D. \& Charlesworth, B. 1987. Inbreeding depression and its evolutionary consequences. Annual Review of Ecology and Systematics 18: 237-268.

Cogniaux, A. 1904-1906. Orchidaceae. Pp. 1-604. In: Martius, C.F.P.; Eichler, A.G. \& Urban, I. (eds.). Flora brasiliensis 3(6). Monachii, Typographia Regia.

Diez, J.M. 2007. Hierarchical patterns of symbiotic orchid germination linked to adult proximity and environmental gradients. Journal of Ecology 95: 159-170.

Faria, R.T.; Rodrigues, F.N.; Oliveira, V.R.O. \& Müller, C. 2004. In vitro Dendrobium nobile plant growth and rooting in different sucrose concentrations. Horticultura Brasileira 22: 780-783.

Hoshi, Y.; Kondo, K. \& Hamatani, S. 1994. In vitro seed germination of four Asiatic taxa of Cypripedium and notes on the nodal micropropagation of American Cypripedium montanum. Lindleyana 9: 93-97.

Knudson,L. 1922. Nonsymbiotic germination of orchid seeds. Botanical Gazette 73: 1-25

Martini, P.C.; Willadino, L.; Alves, G.D. \& Donato, V.M.T.S. 2001. Propagação de orquídea Gongora quinquenervis por semeadura in vitro. Pesquisa Agropecuária Brasileira 36: 1319-1324.

Millner, H.J.; Obeng, A.; McCrea, A.R. \& Baldwin, C.T. 2008. Axenic seed germination and in vitro seedling development of Restrepia brachypus (Orchidaceae). Journal of the Torrey Botanical Society 135: 497-505.

Murashige, T. \& Skoog, F.A. 1962. Revised medium for rapid growth and bio assays with tobacco tissue cultures. Physiologia Plantarum, Copenhagen 15: 473-497. In: Oliveira, L.V.R.; Faria, R.T.; Fonseca, I.C.B.; Saconato, C. 2003. Influência da fonte de carboidrato no crescimento vegetativo e enraizamento in vitro de Oncidium varicosum Lindl. (Orchidaceae). Semina, Ciências Agrárias, 24: 265-272.

Pabst, G.F.J. \& Dungs, F. 1977. Orchidaceae Brasilienses vol. 2. Hildesheim, Brucke-Verlag Kurt Schmersow.

Ramos, M.S.S. 1977. A Orquídea e a sua reprodução pela semente. $2^{\text {a }}$ ed. Campinas, Fazenda Anhumas.

Rao, A.N. 1977. Tissue culture in orchid industry. Pp. 44-49. In: J. Reinert \& Y.P.S. Bajaj (eds.). Applied and fundamental aspects of plant cell tissue and organ culture. Berlim, Springer Verlag.

SMA (Secretaria do Meio Ambiente do Estado de São Paulo) 2004. Lista de espécies da flora ameaçadas de extinção no estado de São Paulo. Resolução SMA - 48, de 21-9-2004. Disponível em: http://www. i b o t. s p. g o v. br/re s o 1 u c a o_s m a 48 / resolucao48.htm (acesso em 10/03/2009).

Sorace, M.; Faria, R.T.; Júnior, C.V.D.; Gomes, G.P.; Berbosa, C.M.; Vieira, F.G.N.; Silva, G.L.; Takahashi, L.S.A. \& Schnitzer, J.A. 2008. Crescimento in vitro de Oncidium baueri (Orchidaceae) em diferentes concentrações de macronutrientes e sacarose. Semina 29: 775-782.

Stancato, G.C. \& Faria, R.T. 1996. In vitro growth and mineral nutrition of the lithophytic orchid Laelia cinnabarina Batem. (Orchidaceae) I: effects of macro and microelements. Lindleyana 11: 41-43.

Stancato, G.C.; Abreu, M.F. \& Furlani,A.M.C. 2008. Crescimento de orquídeas epífitas in vitro: adição de polpa de frutas. Bragantia 67: 51-57.

Takahashi, K.; Ogiwara, I. \& Hakoda, N. 2000. Seed germination of Habenaria (Pecteilis) radiate (Orchidaceae: Orchideae) in vitro. Lindleyana 15: 59-63.

Tremblay, R.L.; Ackerman, J.D.; Zimmerman, J.K. \& Calvo, R.N. 2005. Variation in sexual reproduction in orchids and its evolutionary consequences: a spasmodic journey to diversification. Biological Journal of the Linnean Society 84: 1-54.

Unemoto, L.K.; Faria, R.T.; Vieira, A.O.S. \& Dalio, R.J.D. 2007. Propagação in vitro de orquídeas brasileiras em meio de cultura simplificado. Revista Brasileira de Agrociência 13: 267-269.

Zar, J.H. 1999. Biostatistical analysis. Prantice Hall, Upper Saddle River.

Zettler, L.W. \& Hofer, C.J. 1997. Sensitivity of Spiranthes odorata seeds to light during in vitro symbiotic seed germination. Lindleyana 12: 26-29. 